\title{
The Influence of the Aerobic Training on Muscle Hypertrophy: Literature Review
}

\section{A Influência do Treinamento Aeróbio Sobre a Hipertrofia Muscular: Revisão de Literatura}

\author{
Anderson Geremias Macedo*a; David Michel de Oliveira ${ }^{\mathrm{b}}$ \\ ${ }^{a}$ Anhanguera University, Physical Education Course. SP, Brazil. \\ bFederal University of Goiás, Department of Physical Education/ Special Unit of Sciences. GO, Brazil. \\ *E-mail: andersongmacedo@yahoo.com.br \\ Recebido em: 22/04/2019; Aprovado em: 02/07/2019
}

\begin{abstract}
The literature presents some studies that show that aerobic exercise is responsible for mediating muscle catabolism. Thus, it is interpreted that continuous aerobic exercise produces little or no increase in muscle hypertrophy. The purpose of this review was to demonstrate the effects of aerobic training on muscle hypertrophy alone or in conjunction with resistance training. The present study is characterized by a review of the narrative literature, the databases of SciELO, Google academic and PubMed were consulted. Many studies show that aerobic training (AT) can promote hypertrophic responses in untrained individuals, however, these responses are related to exercise variables such as intensity, volume, frequency, and modality. Higher, continuous or interval intensities, at least $80 \%$ of the HRR, seem to be capable of promoting hypertrophic responses when compared to low intensities. In addition, the training volume may also influence this response and different modalities may have a distinct response to muscle hypertrophy. While the combination of TA and resistance training (TR) corresponds to concurrent training (CT), the literature demonstrates that AT in CT can negatively affect acute and chronic hypertrophic responses depending on intensity, volume, mode and training schedule.
\end{abstract}

Keywords: Exercise. Physical Education and Training. Metabolism.

\section{Resumo}

A literatura apresenta alguns estudos que mostram que exercício aeróbio é responsável por mediar o catabolismo muscular. Dessa maneira, interpreta-se que o exercício contínuo aeróbio produz pouco ou nenhum aumento na hipertrofia muscular. O objetivo desta revisão foi demonstrar os efeitos do treinamento aeróbio sobre a hipertrofia muscular de forma isolada ou em conjunto com o treinamento resistido. O presente estudo caracteriza-se um delineamento de revisão de literatura narrativa, foram consultadas as bases de dados do SciELO, Google acadêmico e PubMed. Muitos estudos mostram que o treinamento aeróbio (TA) pode promover respostas hipertróficas em indivíduos não treinados, entretanto, estas respostas estão relacionadas às variáveis do exercícios como intensidade, volume, frequência e modalidade. Intensidades mais altas, contínuas ou intervaladas, no mínimo $80 \%$ da FCR, parecem ser capazes de promover respostas hipertróficas quando comparado a baixas intensidades. Além disso, o volume do treinamento também pode influenciar esta resposta e diferentes modalidades podem ter resposta distinta sobre a hipertrofia muscular. Enquanto a combinação do TA com o treinamento resistido (TR) corresponde ao treinamento concorrente (TC), a literatura demonstra que o TA no TC pode interferir negativamente nas respostas hipertróficas de maneira aguda e crônica dependendo da intensidade, volume, modalidade e programação de treinamento.

Palavras-chave: Exercício. Educação Física e Treinamento. Metabolismo.

\section{Introduction}

In literature it is not clear the role of aerobic training (TA) on the muscle hypertrophy yet. Some evidences in the literature show that aerobic exercise is responsible for mediating muscle catabolism. ${ }^{1}$ Atherton et al. ${ }^{2}$ led a pioneering study that explained the differences in the responses of the intracellular signaling between two types of exercises. Using an animal model, the isolated plantar flexor muscle of rats was stimulated in two ways, with high frequency intermittently, simulating the stimulus of the resistive exercise or low frequency continuously simulating continuous exercise. The analyzes after the intervention showed that the low frequency stimulation increased the phosphorylation of activated protein kinase (AMPK by adenosine monophosphate ) and high frequency stimulation reduced the phosphorylation of this protein. However, the phosphorylation of threoninelserotonin tyrosine kinase (AKT) protein increased with the stimulus of high frequency and reduced by stimulation of low frequency. Thus, it seems that the intracellular responses via AMPK or AKT may be mediated by the type of exercise. In addition, the opposite intracellular signaling can reduce the adaptive responses of skeletal muscle through the interaction between these two proteins ${ }^{2}$.

However, some studies demonstrate that the TA alone can promote the hypertrophy by increasing the activation of rapamycin (mTOR) a protein important in the process of intracellular signaling in the anabolism process ${ }^{3,4}$. On the other hand, the TA when performed together with resistance training (RT) seems to compromise the hypertrophic adaptations 
promoted by the $\mathrm{TR}^{5.6}$.

The purpose of this review was to demonstrate the effects of aerobic training on muscle hypertrophy alone or in conjunction with resistance training.

\section{Development}

This study aims to outline the literature of review narrative. Books were analyzed regarding the theme and international scientific articles found in the Scielo databases, Google Scholar and PubMed. The following words were used in the Virtual Health Library (VHL) in Portuguese: "hipertrofia muscular", "treinamento aeróbio", "treinamento resistido", "treinamento concorrente" and English: "hypertrophic muscle", " aerobic training", " resistance training", "concurrent training". For the inclusion criterion an analysis was used by checking the studies that showed a relation with the theme of this study.

\subsection{Discussion}

\subsubsection{Effects of aerobic exercise on the hypertrophy}

Some studies in the literature show that TA can promote hypertrophic responses in untrained individuals. With 12 weeks of TA it was able to promote increases in skeletal muscle mass in men and untrained women ${ }^{7}$. This answer seems to be mediated by increased anabolic mediated by insulin signaling; increase in the transport of amino acids; increased blood flow and perfusion in skeletal muscle; reduction of the catabolic signaling proteins as myostatin; increase in the number and size of the mitochondria ${ }^{1,6,7}$. However some training variables should be analyzed in adapting cardiomyopathy induced by TA such as intensity, volume, frequency and type ${ }^{1}$.

Some studies in the literature indicate that higher intensities are necessary for achieving significant muscle growth through the $\mathrm{TA}^{1.3}$. Trape et al. ${ }^{8}$ observed a decrease in the cross-sectional area (AST) of approximately $20 \%$ in the fibers of type I and II after 13 weeks of TA with low intensity for marathon race. This shows that the TA with this intensity is not beneficial to hypertrophy. In spite of not being established in the literature which specific intensity that the TA promotes hypertrophy, it is suggested that the minimum intensity of $80 \%$ of heart rate reserve (HRR) being continuous or intervals seems to promote the best hypertrophic gains induced by TA. The high intensity interval training increased AST at around $24 \%$ in middle-aged individuals with diabetes type 2 , indicating a relation between the intensity of TA and muscular hypertrophy ${ }^{6}$.

The impact of the volume may be dependent on the frequency. Scharwts et al. ${ }^{9}$ compared changes in body composition in young men and elderly patients after 6 months of the TA protocol. The results showed an increase in muscle mass only in elderly men with no change in young men. However, the authors emphasized that adherence to the training protocol was higher for elderly individuals, this way the hypertrophic benefits found in this population are involved directly by the training frequency.

In relation to the hypertrophic responses mediated by different modalities of TA, they are still not clear. Some studies involving this theme has used the cycling and have demonstrated increased muscle growth ${ }^{1}$. Whereas Schwartz et $a l .{ }^{9}$ found an increase in muscle mass only in elderly individuals after 6 months of training protocol involving the modalities of walking and running. On the other hand, Sipila and Suominen ${ }^{10}$ showed that elderly women who underwent combination of step and race with intensities above $80 \%$ of the FCR did not show significant increases after 18 weeks of training. Agreeing with these findings, Jubrias et al. ${ }^{11}$ showed that the AST of elderly men and women did not suffer changes after 24 weeks involving climbing and rowing exercises types being that the training protocol consisted of progressive increase to up to $85 \%$ FCR. Thus, the hypertrophic response induced by other forms of aerobic exercise with the exception of cycling still require further investigation.

\subsubsection{Effects of isolated continuous aerobic exercise on the hypertrophy}

TA is often combined with the TR to accelerate the reduction of body weight, improvement in sports performance, or both. This strategy is called concurrent training (CT), this type of training has demonstrated positive effects on body weight maintenance ${ }^{12}$. However, some evidences show that in TR programs, TA can influence or even affect muscle growth. The negative effects of TC on the hypertrophy is known as chronic interference. The hypothesis of this interference seems to occur by the fact that skeletal muscle is unable to maximize its $=$ morphological and metabolic adaptations to TR or $\mathrm{TA}^{5}$. Similar to the hypothesis of interaction of AMPK-Akt, chronic interference of both training seems to promote competitive adjustments that produce differences in intracellular responses reducing the hypertrophic gains.

Despite the logical foundations of the hypothesis of the interferences of TA in hypertrophic gains induced by RT, these effects are not well understood in humans yet. Some studies have shown that the combination of TA and TR prevents the anabolic signaling induced by $\mathrm{RT}^{13,14}$, others seem that the TA does not affect this signs ${ }^{15}$. However, the acute effect of TC does not seem to affect the muscle proteins synthesis ${ }^{16,17}$.

Although the TA does not affect acutely the synthesis of proteins induced by RT, chronically TA seems to negatively affect muscle growth. Acutely TA can interfere with the TR ability, which can cause fatigue, through the increase of local metabolites and/or depletion of substrate, compromising the TR quality ${ }^{17}$. So, the muscle adaptations are harmed by the reduction of capacity, intensity and reduction in the volume of the session of the TR these being important factors in the process of stimulus to the myofibrillar growth ${ }^{6}$. Another potential mechanism of TC which can compromise the hypertrophic process is overtraining. Because when the 
volume or intensity of training exceeds the capacity of the body recovery the anabolic process is compromised. In addition, stress added by TA can promote an increase of catabolic hormones ${ }^{6}$.

Studies that investigated the results of TC in a chronic form on the muscle adaptations showed that the TA seems to affect the muscle growth. The meta-analysis by Wilson et al. ${ }^{5}$ showing the size of the effects for muscle growth was reduced by around $50 \%$ in weight lifters when the TA was added to RT. Kraemer et al. ${ }^{18}$ showed that after 12 weeks of training, the TR group presented an increase in the AST of the fibers type II, IIa and IIc, whereas the CT group there was only an increase of AST of type Ila fibers. Agreeing with these findings Bell et al. ${ }^{19}$ found similar results with active students, after 12 weeks of TA in the stationary bicycle, TR and TC. The TR group presented an increase in the AST of fibers of type I and II, but the TC increase occurred only in the fibers of type II. However, there are several factors by which the TA can influence the muscle adaptations associated with the RT. In particular, the variables of the TA such as intensity, volume and frequency, modality and programming are fundamental in this answer.

Some evidences suggest that the model called sprint interval training of high intensity is more harmful to the intracellular anabolic flags that the model moderate intensity continuous training ${ }^{19}$. Apparently due to the great interference associated to high intensity training, it seems that TA with lower intensities is more indicated to maximize muscle hypertrophy during TC. However, the results and conclusions of these studies were through acute responses of TC.

The volume can have a big impact on hypertrophic interference associated with $\mathrm{TC}$, potentially related to the symptoms induced by overtraining through muscle catabolism induced by the hormonal system and glycogen depletion $^{20}$. Wilson et al. ${ }^{5}$ revealed a statistically significant negative correlation between muscle hypertrophy and volume (duration and frequency) of TA during TC, specifically the duration presents a strong inverse correlation with muscle hypertrophy.

But the frequency variations of TA may also influence the responses of TC. Jones et al. ${ }^{21}$ demonstrated that individuals have gone through a protocol of RT for 3 days per week and TA were added to this Protocol. The results showed that the circumference of the quadriceps was greater for the protocol that performed only TR $(+4.3 \%)$ for the groups that underwent 1 and 3 days of TA, there was an increase $(+2.8 \%$ and $1 \%$, respectively). These results indicate that the frequency of TA can decrease the muscle hypertrophy in TC.

Among the modalities of TA, the most studied ones are running and cycling. The meta-analysis by Wilson et $a l .{ }^{5}$ revealed that running has particular negative effect on hypertrophic adaptation associated with TR, while cycling seems not to harm the hypertrophic response. In contrast, Panissa et al. ${ }^{22}$ demonstrated that training with high intensity cycling promotes greater harm to strength gains compared to running high intensity before starting the RT.

Depending on the purpose of the training program, the TA can be done in the same session of TR or on alternate days. Some studies have assessed whether the order of TA and TR in the same session of TC may affect intracellular responses. Coffey et al. ${ }^{13}$ investigated the acute effects of a combined training session involving the knee extension and cycling with moderate intensities. Biking performed before exercise resulted in the increase of Akt but a reduction of IGF1 mRNA, in opposite sequence there was an increase in the IGF1 mRNA and increased IGF1 mRNA. On the chronic effect of exercise order of TC in the same session show that the gains of forces are similar regardless of the order ${ }^{23.24}$. Therefore, it seems that the mechanical tension seems not to be affected by order of TA and TR in the same session of TC. Cadore et al. ${ }^{25}$ found similar results of muscle diameter increases regardless if the TA or TR was done first in the TC session. Similarly, Davit et $a l .{ }^{26}$ observed that the changes in the body composition were not affected by the TA performed before or after the TR. These studies seem not clarify safely yet on the importance of the sequence of TA and TR in TC on the muscle hypertrophy. The literature has pointed out that the recovery period between the TA and TR of few hours or alternate days seems to minimize the effects on hypertrophic adaptation ${ }^{5}$. Although the sequence of TA seems to interfere in the hypertrophic response, studies involving this issue are still scarce in the literature.

\section{Conclusion}

Unlike the thought of a large majority of the professionals of physical education, TA can promote muscle hypertrophy in sedentary subjects, being these gains especially in the fibers of type I. However, some factors such as intensity, volume, frequency and modality may influence this response. Training with intensity above $80 \%$ of HR seems to promote greater gains in muscle mass. TC may interfere in the hypertrophic adaptations, particularly the TA with high volume seems to impair the hypertrophy. The negative effects of TC can be minimized if the recovery between TA and TR is a few hours or alternate days.

\section{References}

1. Baechle TR, Earle RW. Essentials of strength training and conditioning. Champaign: Human Kinetics; 2008.

2. Atherton PJ, Babraj J, Smith K, Singh J, Rennie MJ, Wackerhage H. Selective activation of AMPK-PGC-1alpha or PKB-TSC2-mTOR signaling can explain specific adaptive responses to endurance or resistance training-like electrical musclestimulation. FASEB J 2005;19(7):786-8.

3. Mascher H, Andersson H, Nilsson PA, Ekblom B, Blomstrand E. Changes in signalling pathways regulating protein synthesis in human muscle in the recovery period after endurance exercise. Acta Physiol (Oxf) 2007;191(1):67-75.

4. Mascher H, Ekblom B, Rooyackers O, Blomstrand E. Enhanced rates of muscle protein synthesis and elevated 
mTOR signalling following endurance exercise in human subjects. Acta Physiol (Oxf) 2011;202(2):175-84. doi: 10.1111/j.1748-1716.2011.02274.

5. Wilson JM, Marin PJ, Rhea MR, Wilson SM, Loenneke JP, Anderson JC. Concurrent training: a meta-analysis examining interference of aerobic and resistance exercises. J Strength Cond Res 2012;26(8):2293-307. doi: 10.1519/ JSC.0b013e31823a3e2d

6. Murach KA, Bagley JR Skeletal muscle hypertrophy with concurrent exercise training: contrary evidence for an interference effect. Sports Med 2016;46(8):1029-39. doi: 10.1007/s40279-016-0496-y.

7. Konopka AR, Harber MP. Skeletal muscle hypertrophy after aerobic exercise training. Exerc Sport Sci Rev 2014;42(2):5361. doi: $10.1249 /$ JES.0000000000000007

8. Fyfe JJ, Bishop DJ, Stepto NK. Interference between concurrent resistance and endurance exercise: molecular bases and the role of individual training variables. Sports Med 2014;44(6):743-62. doi: 10.1007/s40279-014-0162-1.

9. Schwartz RS, Shuman WP, Larson V, Cain KC, Fellingham GW, Beard JC, et al. The effect of intensive endurance exercise training on body fat distribution in young and older men. Metabolism 1991;40(5):545-51.

10. Sipilä S, Suominen H. Effects of strength and endurance training on thigh and leg muscle mass and composition in elderly women. J Appl Physiol 1995;78(1):334-40.

11. Jubrias SA, Esselman PC, Price LB, Cress ME, Conley KE. Large energetic adaptations of elderly muscle to resistance and endurance training. J Appl Physiol 2001; 90(5):1663-70.

12. Ackel-D'Elia C, Carnier J, Bueno CR Jr, Campos RM, Sanches PL, Clemente AP, et al. Effects of different physical exercises on leptin concentration in obese adolescents. Int J Sports Med 2014;35(2):164-71. doi: 10.1055/s-00331345128.

13. Coffey VG, Zhong Z, Shield A, Canny BJ, Chibalin AV, Zierath JR, et al. Early signaling responses to divergent exercise stimuli in skeletal muscle from well-trained humans. FASEB J 2006;20(1):190-2.

14. Coffey VG, Jemiolo B, Edge J, Garnham AP, Trappe SW, Hawley JA. Effect of consecutive repeated sprint and resistance exercise bouts on acute adaptive responses in human skeletal muscle. Am J Physiol Regul Integr Comp Physiol 2009;297(5):R1441-51. doi: 10.1152/ajpregu.00351.2009.

15. Apró W, Wang L, Pontén M, Blomstrand E, Sahlin K. Resistance exercise induced mTORC1 signaling is not impaired by subsequent endurance exercise in human skeletal muscle. Am J Physiol Endocrinol Metab 2013;305(1):E2232.
16. Donges CE, Burd NA, Duffield R, Smith GC, West DW, Short MJ, et al. Concurrent resistance and aerobic exercise stimulates both myofibrillar and mitochondrial protein synthesis in sedentary middle-aged men. J Appl Physiol 2012;112(12):1992-2001. doi: 10.1152/ japplphysiol.00166.2012.

17. Carrithers JA, Carroll CC, Coker RH, Sullivan DH, Trappe TA. Concurrent exercise and muscle protein synthesis: implications for exercise counter measures in space. Aviat Space Environ Med 2007;78(5):457-62.

18. Kraemer WJ, Patton JF, Gordon SE, Harman EA, Deschenes MR, Reynolds K. Compatibility of high intensity strength and endurance training on hormonal and skeletal muscle adaptations. J Appl Physiol 1995;78(3):976-89.

19. Bell GJ, Syrotuik D, Martin TP, Burnham R, Quinney HA. Effect of concurrent strength and endurance training on skeletal muscle propertiesand hormone concentrations in humans. Eur J Appl Physiol 2000;81(5):418-27

20. Mikkola J, Rusko H, Izquierdo M, Gorostiaga EM, Häkkinen K. Neuromuscular and cardiovascular adaptations during concurrent strength and endurance training in untrained men. Int J Sports Med 2012;33(9):702-10. doi: 10.1055/s-00311295475

21. Jones TW, Howatson G, Russell M, French DN. Performance and neuromuscular adaptations following differing ratios of concurrent strength and endurance training. J Strength Cond Res 2013;27(12):3342-51.

22. Panissa VL, Tricoli VA, Julio UF, Ribeiro N, Azevedo Neto RM, Carmo EC, Franchini E. Acute effect of highintensity aerobic exercise performed on treadmill and cycleergometer on strength performance. J Strength Cond Res 2015;29(4):1077-82. doi: 10.1519/JSC.0000000000000706.

23. Collins MA, Snow TK. Are adaptations to combined endurance and strength training affected by the sequence of training? J Sports Sci 1993;11(6):485-91.

24. Chtara M, Chaouachi A, Levin GT, Chaouachi M, Chamari K, Amri M. Effect of concurrent endurance and circuit resistance training sequence on muscular strength and power development. J Strength Cond Res 2008;22(4):1037-45. doi: 10.1519/JSC.0b013e31816a4419.

25. Cadore EL, Izquierdo M, Pinto SS, Alberton CL, Pinto RS, Baroni BM, et al. Neuromuscular adaptations to concurrent training in the elderly: effects of intrasession exercise sequence. Age (Dordr) 2013; 35(3):891-903. doi:10.1007/ s11357-012-9405-y

26. Davitt PM, Pellegrino JK, Schanzer JR, Tjionas H, Arent SM. The effects of a combined resistance training and endurance exercise program in inactive college female subjects: does order matter? J Strength Cond Res 2014;28(7):1937-45. doi: 10.1519/JSC.0000000000000355 